\title{
Breeding biology of African grey parrot (Psittacus erithacus) in Kom National Park (South-Cameroon) and implications to the species conservation
}

\author{
Ghislain Noé KOUGOUM PIEBENG ${ }^{1 *}$, Simon AWAFOR TAMUNGANG ${ }^{2}$ and \\ Alexis TEGUIA $^{3}$ \\ ${ }^{I}$ Department of Biological Sciences, Faculty of Science, University of Maroua, \\ PO Box 814, Maroua, Cameroon. \\ ${ }^{2}$ Department of Basic Sciences, College of Technology, University of Bamenda, \\ PO Box 2164, Bamenda, Cameroon. \\ ${ }^{3}$ Department of Physiology and Animal Production, Faculty of Agronomy and Agricultural Sciences, \\ University of Dschang, PO Box 222, Dschang, Cameroon. \\ *Corresponding author, E-mail: kougoumghislain@yahoo.fr, Phone: 677381313 or 697642197
}

\section{ACKNOWLEDGEMENTS}

This study was, supported with the financial assistance from PARROTPRO and with the support of Cameroonian Government through the Ministry of Forestry and Wildlife.

\begin{abstract}
Parrots are considered a globally threatened group but, despite that, little is known about the ecology and biology of many species in the wild, this is the case for African grey parrots (Psittacus erithacus). The aim of this work was to study the reproductive biology of the wild grey parrot and its involvement in the conservation of the species. In fact, a follow-up of 40 nests equally distributed in 4 vegetation types (primary forest, secondary forest, cocoa plantation and annual crop plantation) has been done between 2011 and 2013. The length of nesting period per breeding pair in our study was situated between 4 to 5 months from April to early November. The beginning of the nesting in grey parrots coincides with the arrival of the short rainy season and an increase in the availability of food resources. The average egg per pair was $2.5 \pm 0.70$, the mean number of chicks at hatching was $2.26 \pm 0.98$, and only $1.51 \pm 1.16$ nestlings fledged. Nesting success was high $(68.89 \%)$ and varied depending on the nesting phase, year and type of vegetation but without any significant difference. Predation (47.37\%) was the most important cause of nest failure. Nesting success of grey parrots appears to be very high in different habitats, but human predation and deforestation remain the main threats to the parrot population. Additional studies on breeding biology based on large sample and the immediate implementation of conservation actions are essential to avoid future extinction of grey parrots population.
\end{abstract}

(C) 2017 International Formulae Group. All rights reserved.

Keywords: Grey parrot, breeding, biology, success, nest hollows, Cameroon.

\section{INTRODUCTION}

The African grey parrot (GP) is endemic to Africa. It is encountered in Central and West Africa; and marginally in East Africa (Borrow and Demey, 2015). Cameroon is the largest exporter of grey parrots 
(Psittacus erithacus) in Africa and the world, and birds sold come only from the natural environment (Convention on International Trade of Endangered Species of Flora and Fauna (CITES), 2007). The strong commercial exploitation of this species coupled with degradation of their habitat due to many human activities such as agriculture, hunting, urbanization, forestry and mining have caused the loss of nests in the wild (Tamungang et al., 2013). The immediate consequence of these activities is the decline in the population of grey parrots including sexually mature pairs, which leads to a decrease in the reproduction and can even lead to the extinction of the species (Tamungang et al., 2002). After 35 years (between 1981 and 2016) in CITES Annex II (regulated trade), the grey parrot has been classified in Annex I, which means that its trade has become prohibited (CITES, 2016). The species today is in danger of extinction in its range (IUCN, 2016).

Most parrots nest in pre-existing hollows in tall trees that generally emerge above the rainforest (Forshaw, 1989; Tamungang et al., 2013). Three main factors are implicated in the evolution of cavity nesting behaviour: predation pressure, characteristics of cavity microclimate and the availability of cavities (Gibbons and Lindenmayer, 2002). Predation is the greatest cause of nest loss in many birds (Nilsson, 1984). Most studies examining predation have found that birds choose, and are more likely successful in, the strongest/safest cavities (Nilsson, 1984). Very little information is available on the breeding biology and nesting success of African grey parrot.

The aim of this study was to provide the first report on long-term study of the breeding biology of African grey parrots in South Cameroon (Kom National Park) and Africa in general. Here we describe chronology of reproduction, biology of reproduction, factors that affect their reproduction and nesting success.

\section{MARERIALS AND METHODS}

\section{Study area}

This study was carried out in the Kom National Park (KNP) and its surroundings (Figure 1) in South Region of Cameroon, and the data presented covers 3 breeding seasons (2011-2013). The KNP is bordered to the South by Kom River which is the natural border between Cameroon and Gabon, to the North by Mvangane and Oveng SubDivisions, to the West by Lobo River and to East by Djoum Sub-division. He is located in a tropical lowland rainforest between latitudes $2^{\circ} 15^{\prime} 0^{\prime \prime}$ and $2^{\circ} 25^{\prime} 15^{\prime \prime} \mathrm{N}$; and longitudes $12^{\circ} 3^{\prime} 10^{\prime \prime}$ ' and $12^{\circ} 42^{\prime} 0^{\prime \prime}$ E, preferred habitat of African grey parrot, with an area of about 69020 hectares. The vegetation of the study areas comprises primary rainforest, secondary forest, swamp forest and Raphia forest. The mean annual rainfall is about $1750 \mathrm{~mm}$ with rain registered all over the year with two maxima: during September-October (great rainy season) and March-April (small rainy season); the average annual temperature is 24 ${ }^{\circ} \mathrm{C}$ (unpublished rainfall records from Meteorological Centre of Sangmelima, 2013).

\section{Nesting ecology and behaviour}

The grey parrot (GP) usually nests in natural cavities found in the trunks of the big trees in the forest, generally in Terminalia spp (Tamungang et al., 2016). At the beginning of the breeding season, parrots, especially breeding pairs called loudly probably to advertise their presence near the nest site or above the tree harbouring nest hollow (Heinsohn and Legge, 2003). During nesting period, grey parrot are regularly seen near their nest especially while incubating their eggs or raising their nestlings. Nest hollows were found in the trunk or a major branch between 8 and $38 \mathrm{~m}$ above the ground. Grey parrot do not build nests, they occupy only the appropriate cavities in which they add small pieces of wood coming from the tree sheltering the nest, and more often the leaves of the trees (Tamungang et al., 2016). Throughout their life, grey parrots and other 
parrot species use the same nests for nesting (Heinsohn and Legge, 2003).

\section{Data collection}

A systematic search of nests was made in 4 vegetation types (primary forest, secondary forest, cocoa plantation and annual farm crop), moving through vegetation, roads and forest tracks, listening for grey parrot vocalizations. Thus, 40 active nests were located during April-June 2011, each nest was monitored annually until it disappeared (cutting down by man or brought down by wind), failed or abandoned (water infiltration and predation) and during the 3 years of study (1 to 3 nesting cycles per nest or breeding pair). The distribution of these nests were as follow: 10 in primary forest, 10 in secondary forest, 10 in cocoa plantation and 10 in annual crop plantation. The studies of the behaviour of couples during the courtship were made repeatedly on 3 nests in the same site (one visit per week from mid-March to late April every year). The observation was made using binoculars while we hid in a shelter so as not to disturb couples.

Single rope techniques were used to gain access to the nests and each nest tree was climbed once a week during laying period and once every 2 weeks to monitor breeding activity (from hatching to fledging). For each nest visit, records were made of the presence or absence of the breeding activity, the number of eggs, nestlings in the nest and the signs of predation. The causes of nest failure were also noted. The time interval between two egg laying periods was estimated at 3.5 days which allowed us to evaluate the duration of egg laying period. On every nest visit, the condition of the nest hollow, in particular whether it was dry and suitable for breeding or whether it was damp or flooded due to rain, was also noted. The eggs observed in abandoned nests were measured using a calliper.

The duration of the nesting cycle of grey parrot (GP) in the study area was calculated based on the time interval since the initiation of nesting activities (arrangement of nest) for each nest until the young fledged. This time (mean duration) was calculated for three years of study, for a total of 73 nesting cycle, only for couples who have successfully raised their chicks during the three years of study. Nesting success was calculated by the conventional method known also as traditional method (Nice, 1957; Studer, 1991). Here nesting success is the ratio of the number of nests fledging at least one young by the total number of nests monitored x 100 . However, this classic estimate of breeding success brings a bias on the representativeness of the sample in favour of successful nests, which overestimates the reproductive success. Indeed, all nests were not found during their initiation. Moreover, the nests discovered close to their term (hatching or fledging) were subject to a period of smaller risks than those discovered and tracked from the beginning. To overcome this problem, the calculations of reproductive success using the method of Mayfield (1975) were also performed. The period where a reproductive event took place was located in half of the time between two successive visits.

\section{Statistical analysis}

The chi-square test was used for comparison of nesting success by years and vegetation type $(\alpha=0.05)$. The Fisher exact test was also used when the numbers of samples were less than 5. One-way ANOVA was used for comparing the average number of eggs, chicks hatched and the fledglings based on years and type of vegetation at the probability level, $\alpha=0.05$. The normality of each sample was tested using the Kolmogorov and Smirnov method. When the samples did not show normal distribution, a non-parametric test of Kruskal-Wallis was used to compare medians instead of means. The equality between variances was tested using the Bartlett test. 


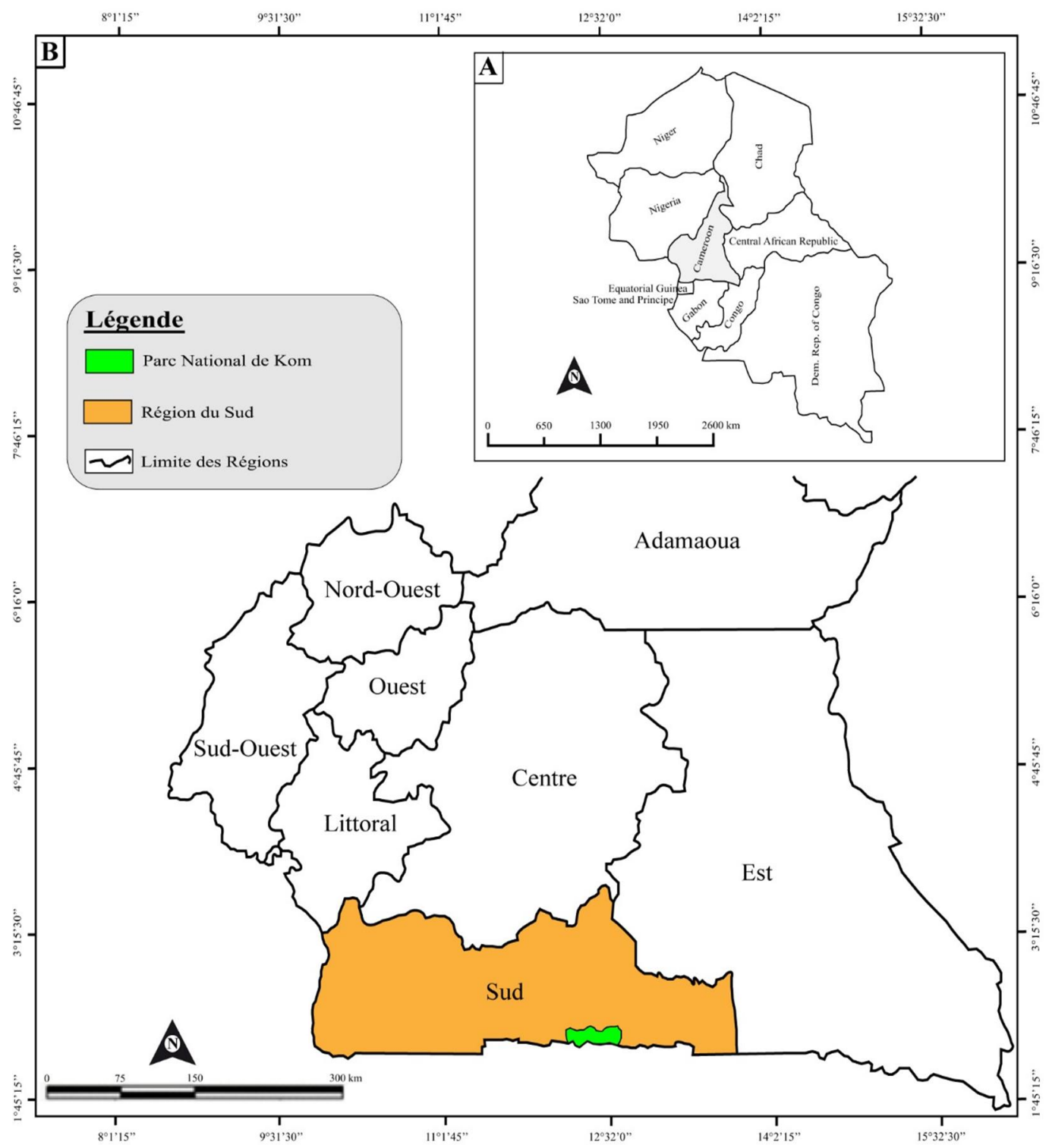

Figure 1: Presentation of the study area.

\section{RESULTS}

\section{Courtship period}

During the three years of data collection, no mating between parrots was observed. The couples were observed in courtship in the branches of tall trees or at the entrance of future nests from March until the end of April. Most mating would have taken place during this period where breeding pairs were showing interest in their potential nests. Before eggs laying, the nest was the subject of particular attention because the couple regularly inspected them. Between March and April, several birds were seen at the nest entrance spirited off pieces of wood with some plant debris falling outside and others inside. Some of these fragments were found inside the nest during the various periods of nest inspection. It was difficult for the remote observation to determine which member of the couple (male or female, both) selected and arranged the nest as the sexual dimorphism in 
GP are not very apparent. During this period, male and female came mostly in the nests during the day and sometimes stayed for 30 minutes. Some couples were carrying leaves of trees into the nests. During this period, contacts between partners become more frequent: more intense mutual grooming with ruffled plumage, friction of the beaks and mutual feeding. One member of the couple (probably the male), would stand still or move on the perch (above the nest or in the branches above it), head down, neck outstretched, and tail fanned, drooping wings, with extension and shortening movements of the neck. This courtship display was accompanied by small whistles.

\section{Laying period}

It appears from Figure 2 that most egg laying (103 of 114 nesting cycle, or $90.35 \%$ ) of GP occur between late April and late May, with $19.3 \%$ (22/114) in late April, 40.35\% $(46 / 114)$ in early May and 30.7\% (35/114) in late May. The large proportion of eggs laid was observed in May with $71.05 \%$ (81 of 114 nests).

\section{Determining the mean length of egg laying period in the study area}

It appears from Table 1 that no significant difference $(P=0.9043)$ was observed between the average duration of clutches per year, and regardless of the type of vegetation $(P=0.9196)$. It nevertheless notes that the average duration of egg laying is slightly higher $(9 \pm 2.32$ days $)$ in primary forest compared to other vegetation types. The average duration of eggs laying for the total nests followed (total number of nesting cycle) was $8.86 \pm 2.44$ days. The duration of eggs laying period however depended on the number of eggs laid which could go beyond 2 weeks for nests containing 5 eggs.

\section{Grey parrot incubation period in the study area and estimate of its duration}

Figure 3 shows that the incubation period in GP is between late April and early July. The end of incubation which also corresponded with the hatching of eggs is mainly at the end of May in 2011, in early June in 2012 and 2013. The majority of nests with eggs recorded hatching in early June of each year. Late incubation at the end of July also matched the late-laying or re-nest. The average duration of incubation is $31,43 \pm 2$ days, all eggs have hatched from the 5 th week (beyond 28 days). According globally to Figure 3, the incubation period of GP in the study area is located between May and June. Indeed, 95 nesting cycle with incubation activity were registered during the three years of study for a total of 117 nesting cycle initiated. This would mean that $81.20 \%$ of GP couples incubating their eggs between the months of May and June. Very little nesting activity (3.42\%) was observed before May and after June (5.98\%).

\section{Rearing period of chicks}

It is clear from figure 4 that the rearing period of GP chicks began in late May and ended in early November when the young fledged. This covered a period of about 5 months for all couples surveyed in the study area. The first flight of chicks in September (7) was observed generally in couples who initiate early (May and June) nesting activity (rearing). In August, regardless of years of observation, all tracked couples raised their young.

\section{Average rearing period of chicks}

Table 2 shows globally that the average length of rearing chicks was significantly higher $(P=0.0062)$ than that obtained in cocoa plantation and annual crops, and regardless of the years. In 2012, the average rearing period of chicks found in primary forest nests was significantly higher $(P=0.0308)$ compared to that of nests found in others vegetation types. The length of the rearing period of chicks in 2013 was significantly higher $\left(\begin{array}{ll}P & <0.05\end{array}\right)$ than in secondary forests and cocoa plantation. On the other hand, this duration was not significant $(P>0.05)$ compared to that of the breeding pairs in annual crop plantations. Depending 
on years, no significant difference $(P=$ 0.8943) was observed between the average lengths of breeding of chicks. The average rearing period of chicks in nests was $115,90 \pm$ 15,36 days, with a confidence interval $(95 \%)$ situated between 112 and 119 days. Overall, the average duration of rearing nestlings was significantly higher in primary forest compared to that of cocoa and annual crops plantations. On the other hand, this term was not significant compared with that of the secondary forest.

\section{Nutrition of nestlings}

The frequency of the nests visit as observed in the different couples appears high in the first month after hatching and then decreases slightly from the second to the fifth month (Table 3). During the rearing period of chicks in the study area (Table 3), no significant differences were observed $(\mathrm{P} \geq$ 0.05 ) on nutrition frequency of nestlings by the couple during the 5 months of observations: first month $(P=0,0592)$; second month $(P=0,2738)$; third month $(P=$ $0,4549)$; fourth month $(\mathrm{P}=0,2653)$ and fifth month $(P=0,4313)$. However, the average number of visits to the nest was higher $(6.89 \pm$ $1.27)$ in the first week after hatching. The females spent most of their time during the first two weeks, to take care of the chicks and feed them. It is the male that goes in search of food, once at the nest; it regurgitates liquid food into the beak of the female which in turn feeds the chicks. From the 4th month, the visit frequency down a notch and is lower the last few weeks before the young fledge the nest (plate 1). Plate 1 shows chicks of 3 and half months, fed at the entrance of the nest by their parents.

\section{Nesting duration of wild grey parrots in the study area}

The average duration of the nesting cycle of GP is about 147 days (146.64 \pm 17.06 SD) with a confidence interval of 142 days for the lower limit and 150 days for the upper limit. This has included monitoring of 73 nests (or clutch). The nesting season of GP is long and is between 4 to 5 months. The reproductive cycle of these birds is even longer and included in addition to the nesting phase, courtship period and emancipation of nestlings after leaving the nests.

\section{Proportion of the number of eggs laid, hatched and fledglings in the study area}

Figure 5 shows that GP couples in the study area laid between 1 and 5 eggs, nests with 2 eggs were the most frequent $(58.12 \%)$, followed by the nests with 3 eggs (31.62\%), those with 1 or 5 eggs were rarely observed. The proportion of the number of juveniles that left the nest was generally small compare to the number of hatched chicks, which in turn was small compared to the number of eggs laid, this for the nests with 2, 3 and 4 eggs (Plate 2). All monitored nests contained at least one egg. Plate 2 shows a nest of GP during the incubation phase.

\section{Mensuration of eggs and determining the average number of eggs per couple of GP}

Eggs of GP have a white colour and are ovoid in shape. A total of 10 eggs (observed in abandoned nests) were taken into account, giving an average length of $38.3 \pm$ $0.52 \mathrm{~mm}$ (with a confidence interval ranging between 37.93 and $38.67 \mathrm{~mm}$ ) and an average width of $31.30 \pm 0.22 \mathrm{mmm}$ (with a confidence interval ranging between 31.14 and $31.46 \mathrm{~mm}$ ). A maximum length of 39.36 $\mathrm{mm}$ and a maximum width of $31.58 \mathrm{~mm}$ were recorded.

The average number of eggs is slightly higher in primary forests $(2.72 \pm 0.80$ eggs $)$ than for other types of vegetation (Table 4). Analysis of variance shows that there was no significant difference $(P \geq 0.05)$ for the average of the eggs number between the types of vegetation and based on years of other hand (Table 4). However the average number of eggs for nests encountered in primary forest was higher in comparison with that obtained in other types of vegetation. In the study area the average number of eggs laid per nest was $2.5 \pm 0.70$. 
Mean number of chicks after hatching by vegetation type and based on years

The Table 5 reveals that no significant difference was observed for the number of chicks at hatching by vegetation types $(P=$ $0.3237)$ and based on years $(P=0.4892)$. However the average number of chicks, like the average number of eggs remained higher in primary forest $(2.52 \pm 1.02)$. This average was lower in secondary forest $(2.13 \pm 0.82)$. The number of fledglings hatching ranged from 0 to 5 chicks with a mean of $2.26 \pm 0.98$ chicks per nest.

\section{Average number of fledglings by vegetation type and based on years}

The ANOVA test showed no significant difference for the average number of chicks which leave the nest (Table 6), according to vegetation types $(P=0.6341)$ and based on years $(P=0.8067)$. The average number of nestlings that left the nest, like the average number of eggs and the average number of hatched chicks remained higher in primary forest $(1.76 \pm 1.27)$. Moreover this mean number of nestlings that flew away from the nest was still low in cocoa plantation (1.38 $\pm 1.15)$. The number of fledglings that left the nest ranged from 0-4 chicks with an average of $1.51 \pm 1.16$ chick for all nests examined in the study area. This average was low compared to the average of eggs laid (2.5 \pm 0.70) during the study period (Table 6).

Plates $3 \mathrm{a}$ and $3 \mathrm{~b}$ show the same nest of GP containing respectively 3 (2011) and 4 chicks (2012), for about 3 and a half months of age, in the village Mebassa in Oveng subdivision filmed at the same periods (early September) in two consecutive years.

\section{Nesting success according to nesting phases and based on years}

The analysis of Table 7 shows that no significant difference was observed for egg success $\left(\chi^{2}=0.08323 ; \mathrm{df}=2, \mathrm{p}=0.9592\right)$, the hatching success $\left(\chi^{2}=0.2768\right.$, df $=2, \mathrm{p}=$ $0.8708)$ and the fledged success of chicks $\left(\chi^{2}\right.$ $=0.1811, \mathrm{df}=2, \mathrm{p}=0.9134)$ based on years. In other words, the different types of nesting success seem not to be influenced by the years. The overall success rates were highest with $60.41 \%$ for the egg success; $90.44 \%$ for hatching success and $66.79 \%$ for fledging success (Table 7). Moreover, the egg success $(60.41 \%)$ shows that there was loss of $39.59 \%$ of broods occurring during the nesting, incubation and rearing of chicks.

\section{Nesting success according to the type of habitat}

From Table 8, it appears that different types of nesting success were higher in primary forest. However, no significant difference was observed for the egg success $\left(\chi^{2}=0.3670 ; \mathrm{df}=3, \mathrm{p}=0.9470\right)$, the hatching success $\left(\chi^{2}=0.04484 ; \mathrm{df}=3, \mathrm{p}=0.9975\right)$ and the fledged success $\left(\chi^{2}=0.1733\right.$; df $=3, \mathrm{p}=$ 0.9818 ) for different types of vegetation.

\section{Determination of nesting success by the method of Mayfield and compared with the traditional method}

The daily survival rate per nest (survival probability) was very high (>99\%) in various types of vegetation. It is higher in the primary forest, followed by secondary forest, then by cocoa plantations and finally annual crop plantations.

The overall way of breeding success was greater than $65 \%$, it was slightly higher in primary forest $(72.41 \%)$ compared to other vegetation type. However no significant difference $(\mathrm{P} \geq 0.05)$ was observed according to vegetation type $\left(\chi^{2}=0.8468\right.$, df $=3, P=$ $0.8382)$. The same observation was made for nesting success according to Mayfield method. The different rates of success obtained by the two methods were very similar (Table 9), nesting success or nest success during the study period using the traditional method being $67.52 \%(79 / 117)$ and against $68.89 \%$ according to Mayfield.

\section{Nesting success of GP by years}

GP nesting success was high in the study area $(67.52 \%$ by the traditional method and $68.89 \%$ by the method of Mayfield), but varied slightly over the years (Table 10). 
However no significant difference $\left(\chi^{2}=\right.$ $5,267 \mathrm{E}-05 ; \mathrm{df}=2 ; P=1$ ) was observed between years.

\section{Causes of nests failure in the study area}

Several causes of nest failure (8) during the nesting period have been identified in the study area. It appears from this figure that predation was the main cause of nest failure (18 of 38 nests, or $47.37 \%$ ), followed by the desertion of nests by the pair $(15.79 \%)$, then by infiltration of rainwater into the nests $(13.16 \%)$ and the falling of chicks from nests $(10.53 \%)$ (Figure 6). Predation in most cases did not result in total loss of the brood, but fewer the number of eggs and especially the number of young birds in the nest. Failures due to the occupation of nests by bees, the natural fall of the trees sheltering the nest by the winds, the slaughter of nests by humans and the congestion of nests by lianas or adjacent vegetation remain low. Predators of GP, represented by the palmnut vulture (Gypohierax angolensis) and various species of hawks were the main predators of the species $(55.56 \%, 10$ of 18 for all predators), followed by men $(27.78 \%)$ and by squirrels $(16.66 \%)$.

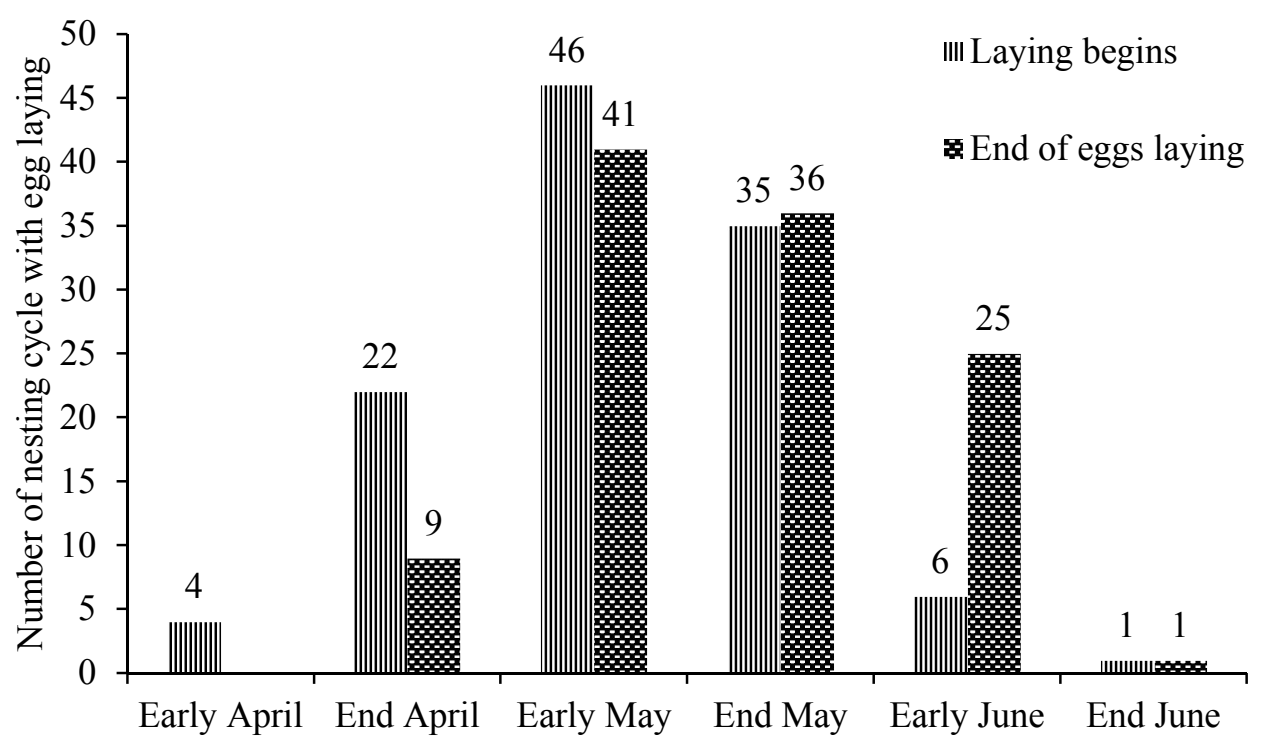

Figure 2: Eggs laying period of grey parrot in the study area.

Table 1: Average duration of clutches per vegetation type.

\begin{tabular}{lccccc}
\hline Year & \multicolumn{5}{c}{ Duration of egg laying } \\
\cline { 2 - 6 } & PF & SF & CP & ACP & Total \\
\hline 2011 & $9,3 \pm 2,41$ & $8,2 \pm 1,93$ & $9,2 \pm 3,01$ & $8,67 \pm 2,65$ & $\mathbf{8 , 8 5} \pm \mathbf{2 , 4 7}$ \\
2012 & $8,6 \pm 2,07$ & $9,3 \pm 2,58$ & $8,2 \pm 1,93$ & $8,6 \pm 2,07$ & $\mathbf{8 , 6 8} \pm \mathbf{2 , 1 3}$ \\
2013 & $9,11 \pm 2,67$ & $9,0 \pm 2,14$ & $9,11 \pm 2,67$ & $9,11 \pm 2,67$ & $\mathbf{9 , 0 9} \pm \mathbf{2 , 7 6}$ \\
Total & $9,0 \pm 2,32$ & $8,82 \pm 2,21$ & $8,83 \pm 2,52$ & $8,79 \pm 2,78$ & $\mathbf{8 , 8 6} \pm \mathbf{2 , 4 4}$
\end{tabular}

$\mathrm{PF}=$ Primary forest; $\mathrm{SF}=$ Secondary forest; $\mathrm{CP}=$ Cocoa plantation; $\mathrm{ACP}=$ Annual crop plantation. Tabulated value are mean $\pm \mathrm{SD}$ of the duration of egg laying. 


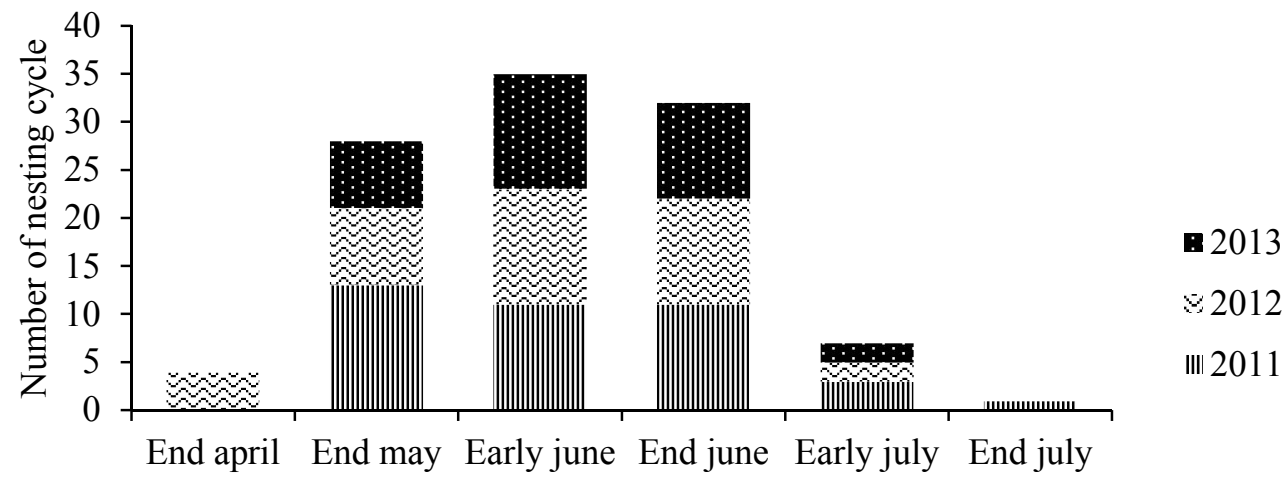

Figure 3: Incubation period of GP in the study area

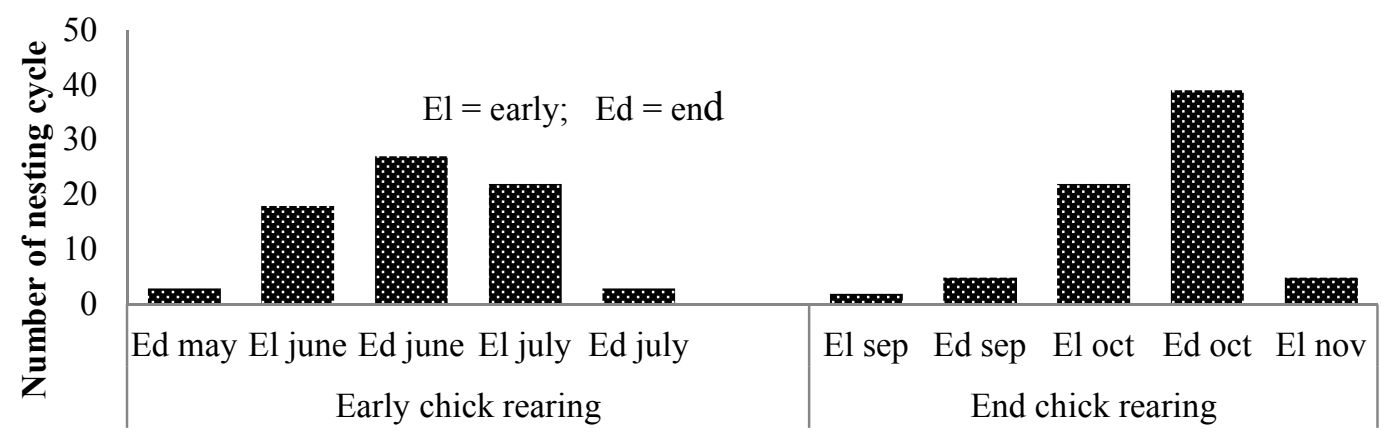

Figure 4: Evolution of the total number of GP nests during the rearing period of chicks in the study area.

Table 2: Average duration of the rearing of nestlings in the study area.

\begin{tabular}{|c|c|c|c|c|c|}
\hline \multirow[t]{2}{*}{ Year } & \multicolumn{5}{|c|}{ Vegetation } \\
\hline & PF & SF & $\mathbf{C P}$ & ACP & Total \\
\hline 2011 & $129,83 \pm 13,67^{\mathrm{a}}$ & $113,83 \pm 20,82^{\mathrm{a}}$ & $113,43 \pm 14,20^{\mathrm{a}}$ & $116,83 \pm 18,72^{\mathrm{a}}$ & $118,28 \pm 17,27$ \\
\hline 2012 & $122,88 \pm 12,74^{\mathrm{a}}$ & $116,2 \pm 28,79^{\mathrm{b}}$ & $111,67 \pm 1,37^{\mathrm{b}}$ & $100,33 \pm 13,11^{\mathrm{c}}$ & $113,44 \pm 17,22$ \\
\hline 2013 & $125,33 \pm 15,55^{\mathrm{a}}$ & $113,5 \pm 4,32^{b}$ & $108,8 \pm 4,55^{\mathrm{b}}$ & $115,17 \pm 6,31^{\mathrm{a}}$ & $116,0 \pm 10,46$ \\
\hline Total & $125,7 \pm 13,47^{\mathrm{a}}$ & $114,41 \pm 18,71^{\mathrm{ab}}$ & $111,56 \pm 8,96^{\mathrm{b}}$ & $110,78 \pm 14,95^{\mathrm{b}}$ & $115,90 \pm 15,36$ \\
\hline
\end{tabular}


Table 3: Average number of visits of the couple to the nest during the rearing period.

\begin{tabular}{|c|c|c|c|c|c|c|}
\hline \multirow{2}{*}{ Couples } & \multicolumn{2}{|c|}{$1^{\text {st }}$ month } & \multirow{2}{*}{$2^{\text {nd }}$ month } & \multirow{2}{*}{$3^{\text {rd }}$ month } & \multirow{2}{*}{$4^{\text {th }}$ month } & \multirow{2}{*}{$5^{\text {th }}$ month } \\
\hline & D & $\mathbf{F}$ & & & & \\
\hline 1 & $7,33 \pm 0,58$ & $6,0 \pm 2,0$ & $4,83 \pm 1,17$ & $4,83 \pm 1,17$ & $5,33 \pm 1,03$ & $5,17 \pm 1,17$ \\
\hline 2 & $5,67 \pm 0,58$ & $5,67 \pm 0,58$ & $5,83 \pm 0,75$ & $5,33 \pm 0,52$ & $4,83 \pm 0,75$ & $4,33 \pm 1,21$ \\
\hline 3 & $7,67 \pm 1,53$ & $6,67 \pm 0,58$ & $5,17 \pm 1,17$ & $4,83 \pm 1,17$ & $4,33 \pm 1,21$ & $4,5 \pm 1,05$ \\
\hline Total & $6,89 \pm 1,27$ & $6,11 \pm 1,16$ & $5,28 \pm 1,07$ & $5,0 \pm 0,97$ & $4,83 \pm 1,04$ & $4,67 \pm 1,14$ \\
\hline
\end{tabular}

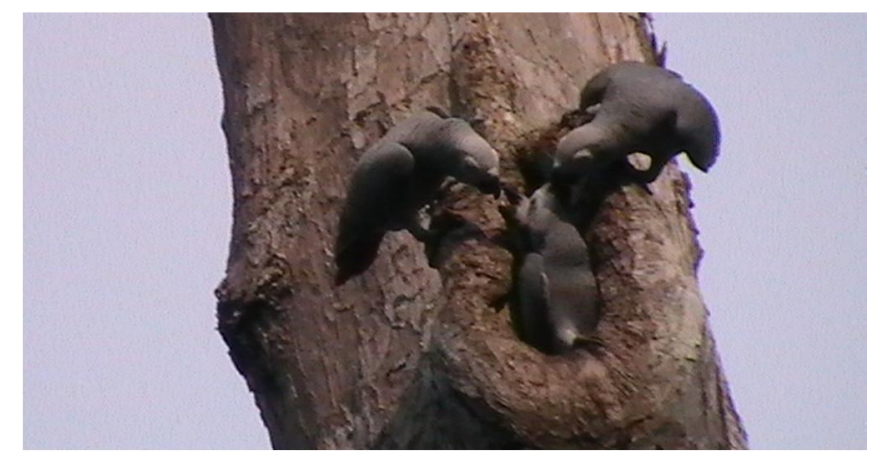

Plate 1: Chicks of 3 and a half months at the entrance of the nest, fed by their parents.

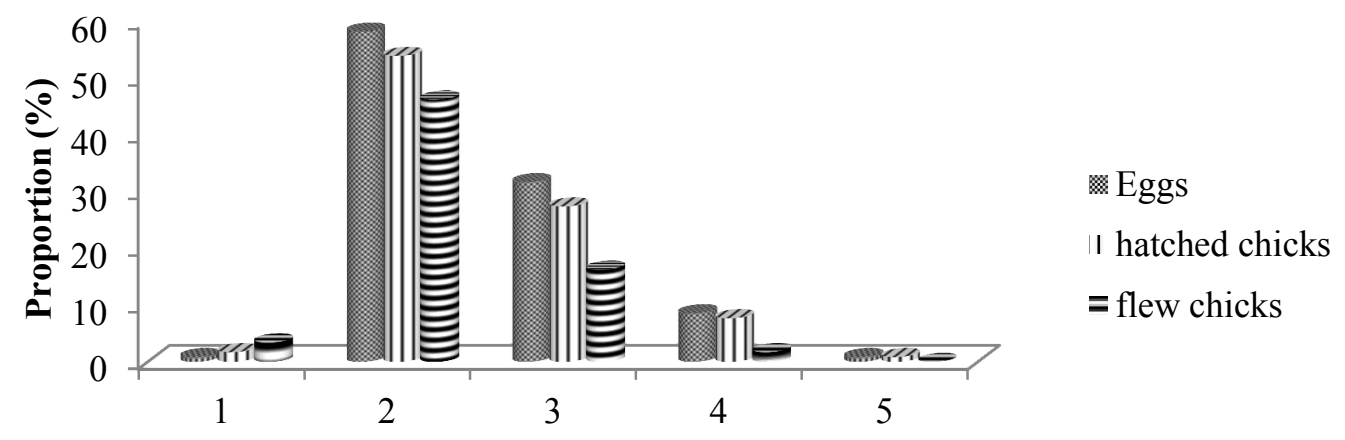

Figure 5: Number of eggs, hatched chicks and flew chicks in the study area

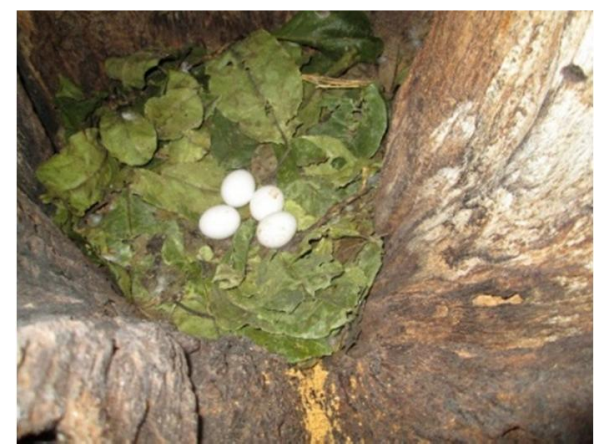

Plate 2: Parrot nest containing four eggs in a cavity inside a trunk of Terminalia superba. 
Table 4: Average number of eggs by vegetation type and based on years.

\begin{tabular}{|c|c|c|c|c|c|}
\hline \multirow[t]{2}{*}{ Year } & \multicolumn{5}{|c|}{ Vegetation } \\
\hline & PF & SF & $\mathbf{C P}$ & ACP & Total \\
\hline 2011 & $2,7 \pm 0,67$ & $2,3 \pm 0,48$ & $2,6 \pm 0,70$ & $2,4 \pm 0,70$ & $2,5 \pm 0,64$ \\
\hline 2012 & $2,6 \pm 0,84$ & $2,5 \pm 0,70$ & $2,3 \pm 0,48$ & $2,4 \pm 0,52$ & $2,45 \pm 0,64$ \\
\hline 2013 & $2,9 \pm 0,93$ & $2,4 \pm 0,52$ & $2,44 \pm 0,88$ & $2,56 \pm 1,01$ & $2,57 \pm \mathbf{0 , 8 3}$ \\
\hline Total & $2,72 \pm 0,80$ & $2,4 \pm 0,56$ & $2,45 \pm 0,69$ & $2,45 \pm 0,74$ & $2,5 \pm 0,70$ \\
\hline
\end{tabular}

Table 5: Average number of chicks after hatching by vegetation type and based on years.

\begin{tabular}{lccccc}
\hline Year & \multicolumn{5}{c}{ Vegetation } \\
\cline { 2 - 6 } & $\mathbf{P F}$ & $\mathbf{S F}$ & $\mathbf{C P}$ & $\mathbf{A C P}$ & Total \\
\hline $\mathbf{2 0 1 1}$ & $2,7 \pm 0,67$ & $2,1 \pm 0,57$ & $2,4 \pm 1,08$ & $2,4 \pm 0,70$ & $\mathbf{2 , 4} \pm \mathbf{0 , 7 8}$ \\
$\mathbf{2 0 1 2}$ & $2,0 \pm 1,25$ & $2,2 \pm 1,03$ & $2,3 \pm 0,48$ & $2,0 \pm 0,94$ & $\mathbf{2 , 1 3} \pm \mathbf{0 , 9 4}$ \\
$\mathbf{2 0 1 3}$ & $2,89 \pm 0,93$ & $2,1 \pm 0,88$ & $1,78 \pm 1,48$ & $2,33 \pm 1,32$ & $\mathbf{2 , 2 7} \pm \mathbf{1 , 1 9}$ \\
\hline Total & $\mathbf{2 , 5 2} \pm \mathbf{1 , 0 2}$ & $\mathbf{2 , 1 3} \pm \mathbf{0 , 8 2}$ & $\mathbf{2 , 1 7} \pm \mathbf{1 , 0 7}$ & $\mathbf{2 , 2 4} \pm \mathbf{0 , 9 9}$ & $\mathbf{2 , 2 6} \pm \mathbf{0 , 9 8}$
\end{tabular}

$\mathrm{PF}=$ Primary forest; $\mathrm{SF}=$ Secondary forest; $\mathrm{CP}=$ Cocoa plantation; $\mathrm{ACP}=$ Annual crop plantation; $\mathrm{SD}=$ standard deviation. Tabulated values are mean \pm SD of number of chicks after hatching in the different breeding pairs.

Table 6: Average number of fledglings by vegetation type and based on years.

\begin{tabular}{|c|c|c|c|c|c|}
\hline & \multicolumn{5}{|c|}{ Vegetation } \\
\hline Year & PF & SF & $\mathbf{C P}$ & ACP & Total \\
\hline 2011 & $1,7 \pm 1,25$ & $1,1 \pm 1,10$ & $1,6 \pm 1,17$ & $1,7 \pm 1,25$ & $1,53 \pm 1,18$ \\
\hline 2012 & $1,7 \pm 1,16$ & $1,5 \pm 1,08$ & $1,3 \pm 1,16$ & $1,3 \pm 1,06$ & $1,48 \pm 1,09$ \\
\hline 2013 & $1,89 \pm 1,54$ & $1,8 \pm 1,03$ & $1,22 \pm 1,20$ & $1,44 \pm 1,13$ & $1,59 \pm 1,21$ \\
\hline Total & $1,76 \pm 1,27$ & $1,47 \pm 1,07$ & $1,38 \pm 1,15$ & $1,48 \pm 1,12$ & $1,51 \pm 1,16$ \\
\hline
\end{tabular}

$\mathrm{PF}=$ Primary forest; $\mathrm{SF}=$ Secondary forest; $\mathrm{CP}=$ Cocoa plantation; $\mathrm{ACP}=$ Annual crop plantation; SD $=$ Standard deviation. Tabulated values are mean $\pm \mathrm{SD}$ of number of fledglings per breeding pairs.

Table 7: The different types of success following the nesting phases.

\begin{tabular}{lllllll}
\hline \multirow{2}{*}{ Year } & \multicolumn{2}{c}{ Egg success } & \multicolumn{2}{c}{ Hatching success } & \multicolumn{2}{c}{ Fledged success } \\
\cline { 2 - 6 } & $\boldsymbol{N} \boldsymbol{f} / \boldsymbol{N e}$ & $\boldsymbol{N}$ & $\boldsymbol{N h} / \boldsymbol{N e}$ & $\boldsymbol{\%}$ & $\boldsymbol{N} \boldsymbol{f} / \boldsymbol{N h}$ & $\boldsymbol{\%}$ \\
\hline $\mathbf{2 0 1 1}$ & $61 / 100$ & 61,00 & $96 / 100$ & 96,00 & $61 / 96$ & 63,54 \\
$\mathbf{2 0 1 2}$ & $57 / 98$ & 58,16 & $85 / 98$ & 86,73 & $57 / 85$ & 67,06 \\
$\mathbf{2 0 1 3}$ & $59 / 95$ & 62,11 & $84 / 95$ & 88,42 & $59 / 84$ & 70,24 \\
Total & $\mathbf{1 7 7 / 2 9 3}$ & $\mathbf{6 0 , 4 1}$ & $\mathbf{2 6 5 / 2 9 3}$ & $\mathbf{9 0 , 4 4}$ & $\mathbf{1 7 7 / 2 6 5}$ & $\mathbf{6 6 , 7 9}$ \\
\hline
\end{tabular}

$\mathrm{PF}=$ Primary forest; $\mathrm{SF}=$ Secondary forest $\mathrm{CP}=$ Cocoa plantation; $\mathrm{ACP}=$ Annual crop plantation; $\mathrm{Nf}=$ number of young fledged; $\mathrm{Ne}=$ number of egg; $\mathrm{Nh}=$ number of egg hatched. 
Table 8: Differents types of nesting success following the phases of nesting and according to the type of vegetation.

\begin{tabular}{lcccccc}
\hline \multirow{2}{*}{ Vegetation } & \multicolumn{2}{c}{ Egg success } & \multicolumn{2}{c}{ Hatching Success } & \multicolumn{2}{c}{ Fledged success } \\
\cline { 2 - 7 } & $\boldsymbol{N} \boldsymbol{f} / \boldsymbol{N e}$ & $\boldsymbol{\%}$ & $\boldsymbol{N} \boldsymbol{h} \boldsymbol{N} \boldsymbol{e}$ & $\boldsymbol{\%}$ & $\boldsymbol{N} / \boldsymbol{N h}$ & $\boldsymbol{\%}$ \\
\hline PF & $51 / 79$ & 64,56 & $73 / 79$ & 92,41 & $51 / 73$ & 69,86 \\
SF & $44 / 72$ & 61,11 & $64 / 72$ & 88,89 & $44 / 64$ & 60,27 \\
CP & $40 / 71$ & 56,34 & $63 / 71$ & 88,73 & $40 / 63$ & 63,49 \\
ACP & $42 / 71$ & 59,15 & $65 / 71$ & 91,55 & $42 / 65$ & 64,62 \\
\hline
\end{tabular}

$\mathrm{PF}=$ Primary forest; $\mathrm{SF}=$ Secondary forest; $\mathrm{CP}=$ cocoa plantation; $\mathrm{ACP}=$ Annual crop plantation; $\mathrm{Nf}=$ number of young fledged; $\mathrm{Ne}=$ number of egg; $\mathrm{Nh}=$ number of egg hatched.

Table 9: Nesting success by the method of Mayfield and comparison with the traditional method.

\begin{tabular}{lcccccccc}
\hline Vegetation & TN & NS & FN & Jn & TS & $\begin{array}{c}\text { Nest } \\
\text { cycle }\end{array}$ & $\begin{array}{c}\text { SMT } \\
(\mathbf{\%})\end{array}$ & $\begin{array}{c}\text { SM (\%) } \\
\left(\mathbf{T S}^{\mathbf{1 4}}\right)\end{array}$ \\
\hline PF & 29 & 21 & 8 & 3932 & 0.9980 & 147 & $\mathbf{7 2 . 4 1}$ & $\mathbf{7 4 . 1 3}$ \\
SF & 30 & 21 & 9 & 3889 & 0.9977 & 147 & $\mathbf{7 0 . 0 0}$ & $\mathbf{7 1 . 1 4}$ \\
CP & 29 & 18 & 11 & 3515 & 0.9969 & 147 & $\mathbf{6 2 . 0 7}$ & $\mathbf{6 3 . 0 8}$ \\
ACP & 29 & 19 & 10 & 3671 & 0.9973 & 147 & $\mathbf{6 5 . 5 2}$ & $\mathbf{6 6 . 9 7}$ \\
Total & 117 & 79 & 38 & 15007 & 0.9975 & 147 & $\mathbf{6 7 . 5 2}$ & $\mathbf{6 8 . 8 9}$ \\
\hline
\end{tabular}

$\mathrm{N}$ = total number of nests; $\mathrm{NS}$ = nests with success; FN = failed nests; Jn = nest day; TS = daily nest survival rate; SM = nest success according to Mayfield; SMT = success of nests by the traditional method.

Table 10: Nesting success of GP by years.

\begin{tabular}{llllllcc}
\hline Year & TN & NS & FN & Jn & TS & SMT (\%) & SM (\%) \\
\hline $\mathbf{2 0 1 1}$ & 40 & 27 & 13 & 5307 & 0.99755 & $\mathbf{6 7 . 5 0}$ & $\mathbf{6 9 . 7 3}$ \\
$\mathbf{2 0 1 2}$ & 40 & 27 & 13 & 4962 & 0.99738 & $\mathbf{6 7 . 5 0}$ & $\mathbf{6 8 . 0 0}$ \\
$\mathbf{2 0 1 3}$ & 37 & 25 & 12 & 4738 & 0.99747 & $\mathbf{6 7 . 5 6}$ & $\mathbf{6 8 . 8 8}$ \\
\hline Total & 117 & 79 & 38 & 15007 & 0.99747 & $\mathbf{6 7 . 5 2}$ & $\mathbf{6 8 . 8 9}$ \\
\hline
\end{tabular}

TN = total number of nests; NS = nests with success; FN = failed nests; Jn = nest day; TS = daily nest survival rates; $\mathrm{SM}=$ nest success according to Mayfield; SMT $=$ success of nests by the traditional method.

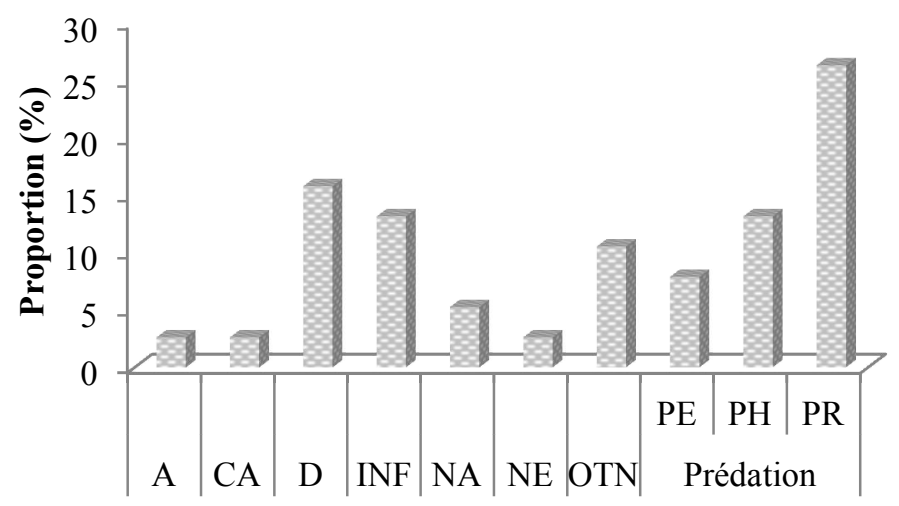

Figure 6: The causes of nests failure during nidification of GP in the study area. A : Bees ; CA : Falling trees; D : Desertion ; INF : water infiltration into the nest; NA : slaughtered nests; NE : cluttered nest; OTN : baby birds fallen from the nest, $\mathrm{PE}$ : squirrel predation; $\mathrm{PH}$ : human predation et PR : predation by raptors. 


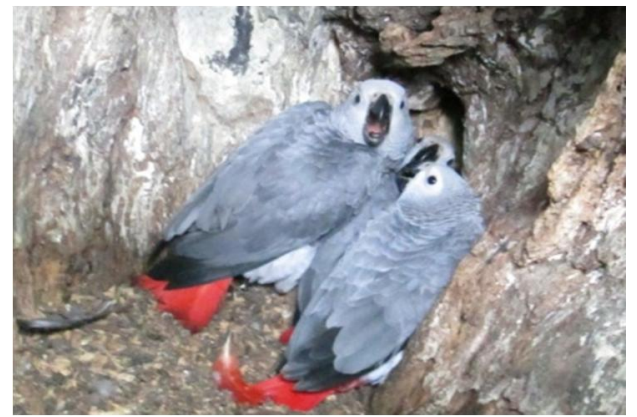

Plate 3a: Nest containing 3 chicks

\section{DISCUSSION}

\section{Courtship period}

Courtship among GP starts from midMarch until the end of April in the study area and is carried out in the branches of tall trees or at the entrance of future nests. This behaviour was observed in the same period during the 3 years of study. This seasonal reproduction observed in GP has already been reported in most forest birds that possess physiological mechanisms adapted to the seasonal reproductive strategy (Stouffer et al., 2013). The breeding season of the birds of the rainforest extends from March to September / October because the gonad growth rate and singing activity in birds are influenced by rainfall, photoperiod and abundance of nutritional resources (Wikelski et al., 2000). Grey parrots, like other birds of the rainforest are able to use the nutrient signal to determine if environmental conditions are favourable for reproduction (Hau et al., 2000). The stay of the GP female in the dark nest during this period promote hormonal changes and development of gonads, mating could also take place during this period (Pratx, 2004). For example, studies of Budgerigars (Melopsittacus undulates) have shown that a combination of nest-site availability, vocal stimulation from males, cavity darkness and position of perches outside the nest box, all influence male and female gonad development (Warburton et Perrin, 2005).

\section{Laying period and its duration}

The eggs laying in GP were observed between early April and the end of June (this

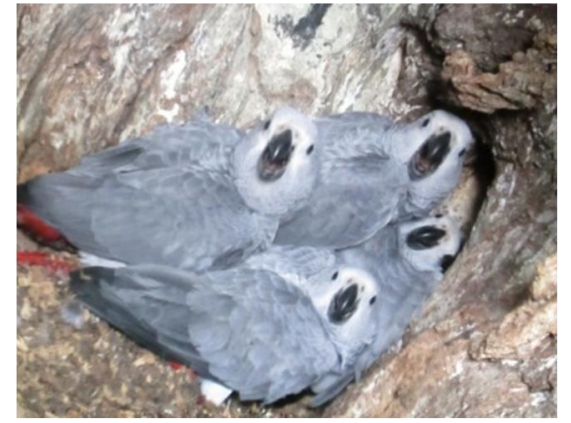

Plate 3b: Nest containing 4 chicks

period corresponds to the short rains season in the study area). The average duration of egg laying was slightly higher in primary forest compared to other types of vegetation. Indeed, the number of eggs laid by forest couple seems to be high compared to other vegetation types. This result indicates that the laying period in the study area is related to the number of eggs laid. It oscillates between 8 and 9 days and even goes beyond 2 weeks for nests containing 5 eggs (observed in primary forest). These results are similar to those obtained by Symes et al. (2004) on Cape parrot (Poicephalus robustus) in the wild.

\section{Incubation period, hatching and duration} Incubation of eggs by GP in the study area was between late April and late July, with a majority of brooding between the end of May and the end of June. Most hatching occurred between early June and late July. The incubation period could not be accurately assessed, but it would be between the 28th and the 35 th day after the laying of the second egg for the nest with more than 2 eggs; and after laying the first egg for the nests with 2 eggs only. Based on our methodology, hatching took less than 3.5 days. These results are similar to those of Pratx (2004) who estimated that the incubation period of grey parrots in captivity is 30 days and hatching taking place between 24 to 72 hours. The further studies will permit to determine the conditions, the exact duration of the incubation and hatching in GP in their natural environment. 
Period, duration of nestlings rearing and that of GP nesting cycle in the natural environment

The rearing of chicks is the longest period of the reproductive cycle of parrots in the study area. It begins early in late May and ends in early November. The majority of takeoffs took place from the third week of October (end of October), which is the main rainy season; the first flights taking place in September and the last in early November. These observations were made throughout the study period, demonstrating the reproductive seasonality of grey parrots, as in most tropical birds (Stouffer et al., 2013). The average chick rearing period obtained is between 112 and 120 days (about 4 months). This duration is greater than that recorded in parrots reared in captivity where it would be between the tenth and thirteenth week (Schratter, 2002). The chicks left the nest after this time and then became interested in food of their natural environment. The period of breeding chicks by GP in the wild in KNP is longer compared to that of captive bred birds; this can be explained by the hostility (scarcity of food resources, rain, predation, etc.) of the natural environment. Indeed, the chicks once out of the nests have to learn very quickly to cope with predators, and in this case only the strongest will survive. It was noted that young birds leaving their nests around the 3rd month after hatching are weaker and more exposed to predators compared to their counterparts who stay long in the nest. Thus the weak birds fly with many difficulties, quickly find themselves on the ground and are captured by men, leopard, tiger cats, raptors and other animals.

The average duration of the nesting cycle (preparation of the nest until the fledging of the chicks) of GP in the study area was $146.64 \pm 17.06$ days with a confidence interval situated between 142 and 150 days. The nesting period is long compared to that of parrots raised in captivity which is between 120 and 130 days (Pratx, 2004). On the other hand, the duration of the breeding period ( 8 months) of GP in Southern Cameroon is close to that of Eclectus parrots (Eclectus roratus) of Australia (Heinsohn and Legge, 2003). During the nesting period, adults (especially females) and chicks over two months were observed in the nests, detaching small pieces, usually dry in the trunk of the tree that they chew. This behaviour would be either a training of the chicks to promote the robustness of their mandibles, or a method of control and prevention against parasites and microbes. Indeed, work on the determination of phytochemical composition, as well as the biological and pharmacological properties of T. superba, has shown the existence in its various extracts (leaves, bark and stems) of chemical groups which can have antiulcerative, anti-diarrheal, analgesic, antiparasites and antimicrobial agents (Kougnimon et al., 2016).

\section{Nutrition of nestlings}

Nutrition of GP chicks is identical to that of other Psittacidae who regurgitate liquid food in the beak of their chick. So, in nature, the food offered to young birds is very diverse, always with a strong protein intake provided by seeds (Tamungang and Ajayi, 2003). Added to soft substances such as buds, leaves, fruit pulp as palm nuts, GP also consume a fine twigs waterlogged. Foods of chicks during the breeding period are also those consumed by adults. Tamungang et al. (2016) identified more than 14 plant species which constitute the diet of GP in Mengame Gorilla Sanctuary-Kom National Park complex.

The frequency of feeding or visit of breeding pair (more than 6 daily visits) in the nest is very important during the first two weeks after hatching. It fell slightly for the remainder of the rearing phase. In fact, during this period, the male feeds the female that remains permanently in the nest; she is exclusively responsible for the nutrition of the chicks during the first weeks. Soon after, the two feed the chicks together. This result shows that more attention should be brought to the chicks during the first weeks after hatching, because they are very vulnerable 
(born without feathers, eyes closed). This result is similar to the studies on captivity breeding in several species of Psittacidae (Stanford, 2005; Carayol, 2007).

\section{Proportion of the number of eggs hatched and the fledglings}

Grey parrot in the study area lay between 1 and 5 eggs with a predominance of nests with two eggs, nests containing 1 or 5 eggs are very rare. These results are similar to studies by Symes and Perrin (2004) who reported that wild grey headed parrots (Poicephalus fuscicollis suahelicus) and Cape parrots (Poicephalus robustus), which are little similar to grey parrot in size lay 2 to 4 eggs. The proportion of fledglings is still low compared to the proportion of eggs hatched. This result is explained by the behaviour of parents who begins to spend more time away from the nest in search of food. Indeed, exposed nests, unattended and are coveted by predators which prey on chicks and kills them. In the absence of parents some older chicks often venture close to the nest entrance and inadvertently fall. Some parents are killed or captured during the nesting period, abandoning nests with chicks that did not survive.

\section{Grey parrot eggs measurement in natural environment}

Grey parrot eggs are white, allowing the couple to better distinguish in the dark nest. The eggs lengths vary between 37.93 and $38.67 \mathrm{~mm}$, a width of between 31.14 and $31.46 \mathrm{~mm}$. A maximum length of $39.36 \mathrm{~mm}$ and a maximum width of $31.58 \mathrm{~mm}$ were recorded. These dimensions are comparable to those obtained for the measurement (approximately $39 \times 31 \mathrm{~mm}$ ) of captive parrots eggs (Pratx, 2004).

\section{Average number of eggs laid, hatched and fledglings by vegetation type, and based on years}

The average number of eggs laid, the hatched chicks and fledglings in the study area is higher in primary forest regardless of the stage of nesting compared to other vegetation types. This result shows that the primary forest is the original habitat, the ideal environment for the breeding of parrots. In fact, in this habitat, perturbations linked to human activities are negligible.

\section{Nesting success in GP}

The overall nesting success of GP recorded in the study area is $67.52 \%$ by the traditional method and $68.89 \%$ according to the Mayfield method. Both rates remain almost identical, because all detected nests were monitored from the beginning of nesting until the failure or success of the nests (fledging). This breeding success is very high compared to results obtained in the South West Region of Cameroon that was 25\% and $0 \%$ for parrots of Nigeria (Pain et al., 2006). This high rate obtained in our study area is due to the less important anthropogenic pressures during the study period, compared to other sites (Southwest region). The taking of birds in the wild and deforestation for the creation of large industrial plantations in the South west Region has a large negative impact on parrots nesting success in the area. This impact is more accentuated by the proximity of Nigeria, the most populous country in Africa. This breeding success of GP in the study area although high, remains low compared to the results for other African parrots such as the Cape parrot (Poicephalus robustus) in South Africa with $78 \%$ of nests success (Wirminghaus et al., 2002), more than $75 \%$ for grey-headed parrot (Poicephalus fuscicollis) of Zimbabwe and South Africa (Symes and Perrin, 2004). It has already been shown that nesting success is generally higher for species that nest in tree cavities (Brawn et al., 2011). In fact, benefits of cavity nesting include shelter from external elements, energy conservation, and greater protection from predators (Rhodes et al., 2009). The high hatching success $(92 \%)$ was comparable to that of other parrots species (Masello and Quillfeldt, 2002; Heinsohn and Legge, 2003). 
Nesting success based on years and type of vegetation

The different types of nesting success are not influenced by years or by type of vegetation despite minor variations. Yet several studies have shown that the probability of nest survival is also influenced by habitat and nesting sites (Burke and Nol, 2000; Newmark and Stavley, 2011), the types of nests and nesting phases (Brawn et al., 2011). This result also shows that the behaviour of couples (Supervisory degree of nest) regardless of the type of vegetation is of major importance in contributing to the breeding success. The hatching success is highest compared to egg success and success for take-off. In fact, failures are more frequent during the rearing phase of the chicks, because the couples regularly visit the nests, which attract the attention of the predators who attack the chicks. This result is also explained by the occurrence of failures from laying to fledging.

\section{Causes of nests failure of GP in the study area}

Among the identified causes of nest failure, only predation represents about $47.37 \%$ of losses. The main predators of GP in the study area are raptors (hawks and palm nut vultures) followed by humans and squirrels. Other causes of failures (occupation of nests by bees, the natural fall of trees, water infiltration into the nest, the fall and death of chicks, nests congestion by adjacent vegetation) have little impact on the breeding parrots. It has already been shown that the major cause of nest failure is the predation of eggs and chicks (Burke and Nol, 2000; Flaspöhler et al., 2001; Tewksbury et al., 2006). Very little failures $(5.26 \%)$ were recorded during the incubation period. In fact during this period at least one partner (usually the female) remained in the nest and ensured at the same time his continuing supervision.
The high failure rate recorded during the rearing phase of nestlings would be because during this period, couples regularly left the nest to forage, exposing their young to predators. Some members of couples (1 or both of the pair) were sometimes killed in the forest by hunters or caught, so abandoning their nests containing either eggs or nestlings.

\section{Breeding biology and contribution to the management of species}

The main problem facing the GP during the breeding period is the scarcity of suitable nest (Tamungang et al., 2016). The availability of such nests is the first nesting step, once the couples are formed. The need for an appropriate support and concealment as well as the need for protection against opposing forces of the environment governs the selection of the site. In general birds that nest in natural cavities (like the Grey Parrot) are more restricted in their choice of suitable nests than those that create nest cavities (like woodpeckers) and those that build nests using twigs on a tree (like warblers) (Rhodes et al., 2009). Moreover, a bird that builds its nest is more flexible in searching for a more suitable site and use better materials for its construction. An ideal nest becomes difficult for a Grey Parrot to find, since it relies on natural agents to create a suitable nest cavity (Tamungang et al., 2016). The fidelity of breeding pairs of GP to nest site and scarcity of nests, coupled with the degradation of their natural habitat by human activity considerably decreases the number of breeding pairs annually. This could lead in the near future, if nothing is done, to a significant downsizing or disappearance of the species.

The knowledge of nests characteristics, breeding biology, the interactions between GP and other environmental components, and the phenology of reproduction of the species is presented today as a solution for the conservation and management of these birds 
in the countries of its range distribution. Indeed, controlling the reproduction of grey parrot and the problems it encounters will enable the authorities in charge of forests and wildlife to find suitable solutions for the sustainable management of the species in Cameroon and even in Africa.

\section{Conclusion}

This study showed that the African grey Parrot, which is considered in danger of extinction, has specific requirements for nesting and nest site-fidelity, characteristics that could be problematic in a scenario of increasing loss and fragmentation of habitat. Although rates of nesting success appeared to be high, over $30 \%$ of chicks die during their stay in the nest. The development of defence systems against predators during incubation and rearing phase could also help increase nesting success of GP in their natural environment. Nowadays grey parrots adapt to changes in their natural environment, but the increase in human pressure is a serious threat to the survival and reproduction of this species. The breeding season of grey parrots lasts for about 8 months (late March to early November). This knowledge will allow better selective taking of bird specimens (young birds) in the wild. To this end, catches can be done outside the nesting season (midNovember to February) and during the nesting period exclusively in dorm sites. Because only breeding pairs sleeping near their nest in different types of vegetation and other (nonbreeding and young birds) in the dorms. The studies of breeding biology of grey parrots on a large sample will provide further information required for the management and conservation of the species.

\section{COMPETING INTERESTS}

The authors declare that they have no competing interests.

\section{AUTHORS' CONTRIBUTIONS}

This work is the fruit of a perfect collaboration between the University of Dschang and the Ministry in charge of Forests and Wildlife, Initiated and realized by GNKP and SAT, on the supervision of AT.

\section{ACKNOWLEDGEMENTS}

Thanks to the authorities of Oveng Sub-Division, the Conservator of Kom National Park-Mengame Gorilla Sanctuary Complex (Mr Zang Mbarga), Eco-guards, Rural Communities, tree climbers, porters, and Forest guides for their services and hospitality. Immense thanks for the logistic support from the staff of the Laboratory of Biology and Applied Ecology (LABEA), Department of Animal biology of the University, Cameroon.

\section{REFERENCES}

Borrow N, Demey R. 2015. Oiseaux de l'Afrique de l'Ouest. Ed Delachaux et Niestlé: Paris.

$511 \mathrm{p}$

Brawn JD, Angehr G, Davros N, Robinson WD, Styrsky JN, Tarwater CE. 2011. Sources of variation in the nesting success of understory tropical birds. Journal of Avian Biology, 42: 61-68. DOI:10.1111/j.1600048X.2010.04897.x.

Burke DM, Nol E. 2000. Landscape and fragment size effects on reproductive success of forest-breeding birds in Ontario. Ecological Applications, 10: 1749-1761. DOI: 10.1890/10510761(2000)010[1749:LAFSEO]2.0.CO;2

Carayol BF. 2007. Besoins Alimentaires et pratiques de l'alimentation des Psittacidés granivores, Thèse de Médecine Vétérinaire, Toulouse. 97p

CITES. 2007. Research on web site: http:/www.cites.org (16/04/2007). 
CITES. 2016. Examen des propositions d'amendement des annexes I et II (cas de Psittacus erithacus). Dix-septième session de la Conférence des Parties, Johannesburg, Afrique du Sud, 19p

Flaspohler JD, Temple AS, Rosenfield NR. 2001. Species-specific edge effect on nest success and breeding bird density in a forested landscape. Ecological Applications, 11(1): 32-46. DOI: 10.1890/10510761(2001)011[0032:SSEEON]2.0.CO;2

Forshaw JM. 1989. Parrots of the World (3rd revised edn). David and Charles, Newton Abbot: London.

Gibbons P, Lindenmayer D. 2002. Tree Hollows and Wildlife Conservation in Australia. CSIRO Publishing. 211p.

Gibbons P, Lindenmayer DB, Barry SC, Tanton MT. 2000. Hollow formation in eucalypts from temperate forests in south-eastern Australia. Pacific Conservation Biology, 6: 218-228. https://doi.org/10.1071/PC000217

Hau M, Wikelski M, Wingfield CJ. 2000. Visual and Nutritional Food Cues FineTune Timing of Reproduction in a Neotropical Rainforest Bird. Journal of Experimental Zoology, 286: 494-504.

Heinsohn R, Legge S. 2003. Breeding biology of the reverse-dichromatic, co-operative parrot Eclectus roratus, J. Zool. 259:197-208. DOI: 10.1017/ S0952836902003138

IUCN. 2016. The IUCN Red List of Threatened Species. Version 2016-3. $<$ www.iucnredlist.org $>$. (26/04/2017).

Kougnimon F, DougnonV, Anago E, Bankole H, Soumanou M, Loko, F. 2015. Propriétés biologiques et pharmacologiques de Terminalia superba Engl. et Diels (Combretaceae): Synthèse bibliographique. Algerian Journal of Natural Products, 3(2): 164176.
Masello JF, Quillfeldt, P. 2002. Chick growth and breeding success of the Burrowing Parrot. Condor, 104: 574-586. DOI:10.1650/0010-5422(2002)104 [0574:CGABSO]2.0.CO;2

Mayfield HF. 1975. Suggestions for calculating nest success. Wilson Bulletin, 87: 456-466.

Newmark DW, Stavley RT. 2011. Habitat fragmentation reduces nest survival in an Afrotropical bird community in a biodiversity hotspot. Proceedings of the National Academy of Sciences, 108(28): 11488-11493. DOI: $10.1073 /$ pnas. 1104955108

Nice MM. 1957. Nesting success in altricial birds. Auk., 74: 305-321. DOI: 10.2307/ 4081922

Nilsson SG. 1984. The evolution of nest-site selection among hole-nesting birds: the importance of nest predation and competition. Ornis Scandinavica, 15: 167-175. DOI: $10.2307 / 3675958$

Pain DJ, Martins TLF, Boussekey WM, Diaz SH, Downs CT, Ekstrom JM, Garnett S, Gilardi JD, McNiven D, Primot P, Rouys S, Saoumo'e M, Symes CT, Tamungang $\mathrm{S}$, Theuerkauf J, Villafuerte D, Verfailles L, Widmann P, Widmann ID. 2006. Impact of protection on nest take and nesting success of parrots in Africa, Asia and Australasia. Animal Conservation, 9: 322-330. DOI: $10.1111 / \mathrm{j} .1469$ 1795.2006.00040.x

Pratx I. 2004. Les perroquets gris d'Afrique, Psittacus erithacus. Thèse de Doctorat d'Etat en pharmacie, Université de Toulouse II, $244 \mathrm{p}$.

Rhodes BK, O'Donnell CFJ, Jamieson IG. 2009. The roles of predation, microclimate and cavity abundance in the evolution of New Zealand's treecavity nesting avifauna. Notornis, 56: 190-200. DOI: 10.1525/cond.2009. 080030 
Schratter D. 2002. Le Perroquet Gris $d u$ Gabon. Eugen Ulmer Eds: Paris. 96 p.

Stanford M. 2005. Nutrition and Nutritional Disease, BSAVA Manual of Psittacine Birds $\left(2^{\text {nd }}\right.$ Edn). British Small Animal Veterinary Association; 136-154.

Stouffer PC, Johnson EI, Bierregaard Jr RO. 2013. Breeding seasonality in Central Amazonian rainforest birds. The Auk, 130(3): 529-540. DOI: 10.1525/auk.2013.12179

Studer A. 1991. Taux de réussite des nids de trois peuplements d'oiseaux du Brésil et stratégies adaptatives. Thèse en vue de l'obtention du Diplôme de Recherches Doctorales en Sciences naturelles (ancien Doctorat d'Université), Université de Nancy I. 240 p.

Symes CT, Perrin MR, 2004. Breeding biology of the Grey headed Parrot (Poicephalus fuscicollis suahelicus) in the wild. Emu., 104: 45-57.

Tamungang SA, Ajayi SS. 2003. Diversity of food of the Grey Parrot in Korup National Park, Cameroon. Bulletin of Africa Bird Club., 10(1): 33-36.

Tamungang SA, Ayodele IA, Akum ZE. 2002. Basic Home Range for the Conservation of the African Grey parrot in Korup National Park, Cameroon.
Journal of the Cameroon Academy of Science, 2(3): 155-160.

Tamungang SA, Cheke RA, Kougoum GP, Ntiri ES. 2013. Linking population size to conservation needs of the Grey Parrot in Cameroon. International Journal of Biodiversity and Conservation, 5(8): 478-485. DOI: 10.5897/IJBC2013.0569

Tamungang SA, Kougoum PGN, Teguia A. 2016. Nest Characteristics for the Conservation of the Grey Parrot in Cameroon. Journal of Ecology and The Natural Environment, 8(9): 142-154. DOI: $10.5897 /$ JENE2016.0601

Tewksbury JJ, Garner L, Garner S, Lioyd DJ, Saab V. 2006. Test of landscape influence: nest predation and brood parasitism in fragmented ecosystem. Ecology, 87(3): 759-768. DOI: 10.1890/04-1790

Wikelski M, Hau M, Wingfield CJ. 2000. Seasonality of reproduction in a neotropical rain forest bird. Ecology, 81(9): 2458-2472. DOI: 10.1890/00129658(2000)081[2458:SORIAN]2.0.CO;2

Wirminghaus JO, Downs CT, Perrin MR, Symes CT. 2002. Breeding biology of the Cape Parrot, Poicephalus robustus. Ostrich, 72(3-4): 159-164. DOI: 10.2989/00306520109485310. 